beforehand which would enable one to say definitely whether bladder-neck resection would relieve a patient's retention. With regard to pudendal neurectomy, rhizotomy and alcohol block, one could give a preliminary test in the form of a shortacting local anaesthetic, either nerve block or into the theca, and say whether it was likely that the permanent destructive operation would achieve the desired result. There was unfortunately no reliable test as far as the bladder-neck was concerned. Any injection would, of course, increase the resistance at the neck of the bladder by local swelling and he did not think that anyone had found this very satisfactory. With regard to the reason for resection of the external sphincter, originally they had done this operation in precisely those patients who had no spasticity and therefore were not amenable to destructive neurosurgical procedures or blocks. Often in lower motor neurone cases there was some sort of resistance which was not spastic nor was it a stricture, but division of that region produced relief. Later, they extended the operation to cover cases who had a spastic obstruction there but in whom they did not want to do destructive neurosurgical procedures because in young cases one did not want to make them impotent. This was how the matter could rest historically.

With regard to incontinence, to answer Dr. Hardy if one had a patient with a big residual urine he might be made completely continent by eliminating his residual urine-he might have some control but be unable to manage if he had a big residual urine. In the same way, a low sacral lesion might be made completely continent by relieving his residual urine; he could empty by straining and tell when the bladder was full, and if he did not leave it too long he would not even have stress incontinence. With regard to complete upper motor neurone lesions, the patients were incontinent and could be trained to adapt themselves to their incontinence but they could not be made continent by bladder-neck resection or anything else. One could relieve their upper urinary tracts and their infection by reducing the resistance at the outlet of the bladder. Mr. Gibbons said that Mr. Ross had already corrected his initial statement regarding early resection of the bladder-neck and he now confirmed that they did these operations early because they thought they were good for the patients. They had perhaps felt a bit of pressure in the past but they were doing the right thing now on their own account and he apologised if he had maligned his neurological colleagues.

\title{
THE MANAGEMENT OF PATIENTS WITH INJURY OF THE CERVICAL SPINE USING BLACKBURN SKULL CALIPERS AND THE STRYKER TURNING FRAME
}

\author{
By PhIllip Harris, F.R.C.S.E., F.R.C.P.E., F.R.C.S.(Glas.), \\ and Peter H. T. Wu, F.R.C.S., M.R.C.P.E. \\ Department of Surgical Neurology, Royal Infirmary, Edinburgh, and \\ Spinal Injury Unit, Edenhall Hospital, Musselburgh
}

SERIOUS injuries of the cervical spine are becoming increasingly common, mainly due to road accidents and to falls, but with expert medical, nursing and rehabilitation care, many patients with these injuries can now be salvaged and eventually returned to a useful life.

The management of patients with severe damage to the cervical spine, with or 
without involvement of the neural elements, is a major undertaking requiring the best possible hospital facilities. The availability of trained staff varies from hospital to hospital and from country to country, and therefore safe, simple, and reliable methods of management are essential for the proper care of these patients.

Since 1956, in the Department of Surgical Neurology in Edinburgh and in the Spinal Injury Unit, Edenhall Hospital, Musselburgh, the earlier hospital management of patients with severe cervical spine injury has been carried out using Blackburn skull calipers (Blackburn, I938), and the Stryker turning frame (Stryker, 1939). Certain modifications have been made to these pieces of equipment by Dott, Gillingham and Harris.

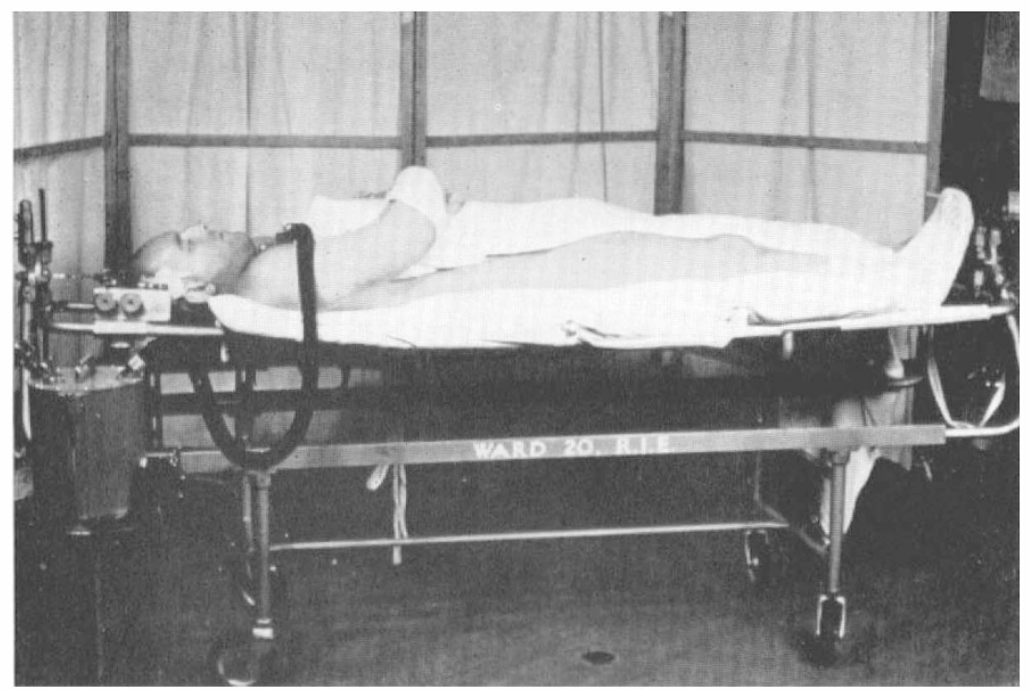

FIG. I

Patient on Stryker turning frame with Blackburn skull calipers in place. (Note humidifier.)

In the period prior to I956 Blackburn skull calipers were used with the patient lying on an anterior or posterior plaster of paris shell. So that the patient's head could remain free and head traction could be continuously applied, a metal hoop with a protruding rod ('bowsprit') was incorporated in the head end of the plaster shell. The outer parts of the Blackburn skull calipers rested either directly on the hoop, or on wooden runners which were slotted and attached to the hoop. A wire from the Blackburn skull calipers passed over a pulley which was fixed to the rod extending from the metal hoop and weights were attached to this wire for cervical traction (Dott's modification). However, the Stryker turning frame was found to have many important advantages over plaster shells (Stryker, I939; Skinner, 1946, 1952), and traction or immobilisation of the cervical spine is achieved by the Blackburn skull calipers which rest on a metal caliper support (Gillingham's modification) which is fixed to each of the frames (anterior and posterior) of the Stryker turning frame (fig. I).

The Blackburn skull calipers appear to have several advantages over other forms of skull traction, and the modification designed by Dott of a metal sleeve 
which replaces the previous 'washer' allows the skull to be firmly gripped by the caliper. Thus the caliper will not slip more deeply into the head nor will it come out accidentally (fig. 2). ${ }^{1}$ A further modification to the caliper supports is being

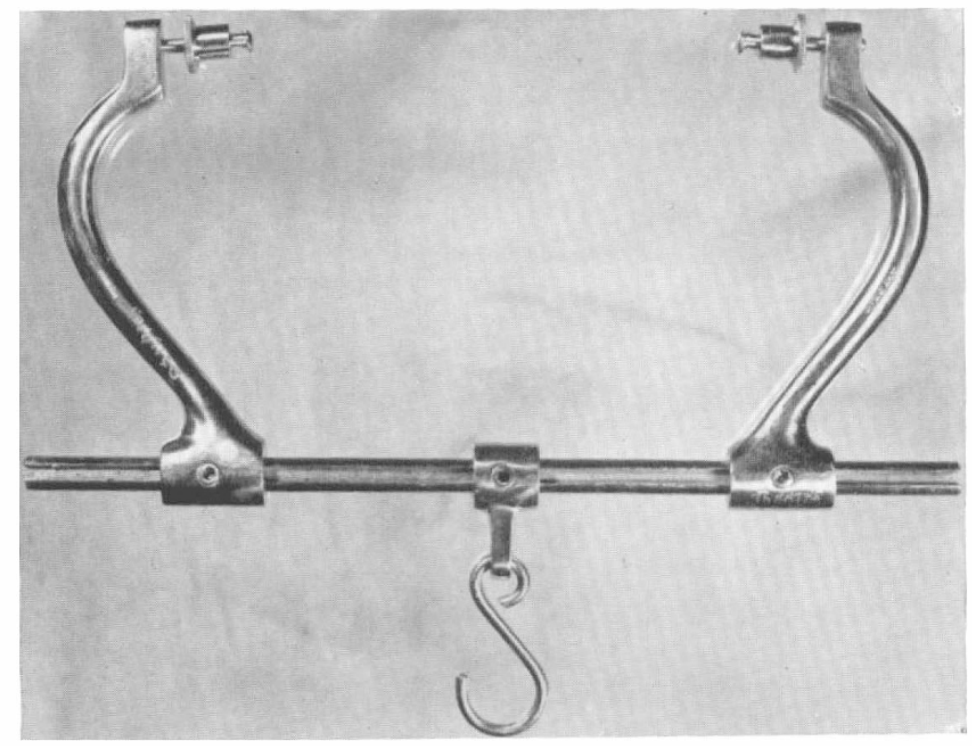

FIG. 2

The modified Blackburn skull calipers.

made, to allow a greater range of movement of the Blackburn skull calipers, permitting easier reduction of subluxations and dislocations of the cervical spine, also permitting the use of 'fixed-traction', and reducing friction between the Blackburn skull calipers and the caliper supports (Harris's modification).

We feel that the Blackburn skull calipers/Stryker turning frame technique for the management of certain patients with cervical spine injury is a very satisfactory one, and is tolerated very well by patients (Harris, I963).

\section{TECHNIQUE OF APPLICATION OF BLACKBURN SKULL CALIPERS}

The insertion of the calipers is usually carried out under local anaesthesia, with the patient lying supine on the operating table and the head firmly supported on a head rest or on a sorbo rubber covered horse-shoe or ring. Twin vertical incisions carried down to bone are made in the temporal regions, and self-retaining retractors are inserted. With a Hudson brace and a quarter inch bit with a guard (fig. 3), a hole is made $7 \mathrm{~cm}$. above and about I or $2 \mathrm{~cm}$. behind the external auditory meatus, in each squamous temporal bone and is carried down to the dura mater. The pin of each arm of the caliper is inserted through the opening in the skull so that the end-plate lies between the skull and the dura mater. It is noted that some surgeons prefer to insert the pin to a depth which allows the end-plate tip to lie in the

1 The modified Blackburn skull calipers are manufactured by Messrs. Down Brothers and Mayer \& Phelps, Ltd., Church Path, Church Road, Mitcham, Surrey. 


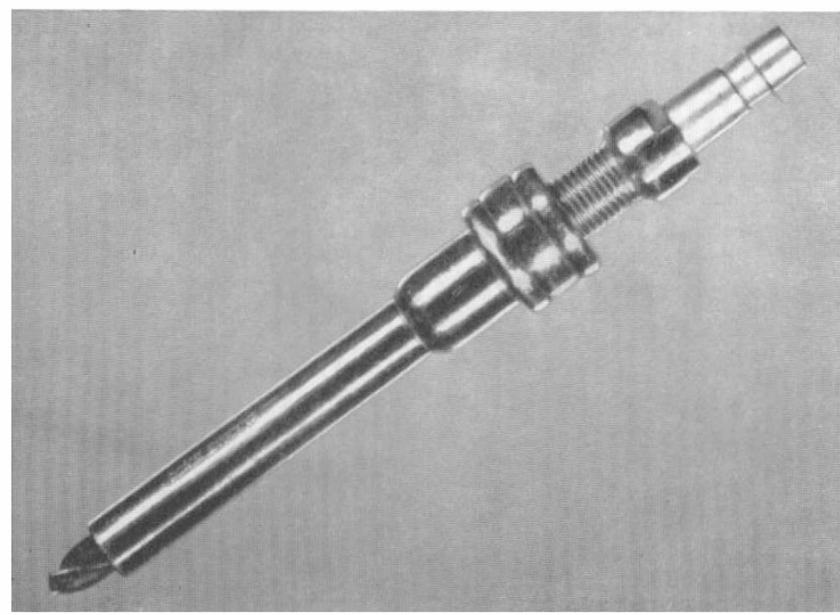

FIG. 3

$\frac{1}{4}$ in. bit with guard.

diploë, between the inner and outer tables of the skull. But the authors find that a firmer and safer pull on the skull is obtained by having the end-plate lie between the inner table of the skull and the dura mater, and this technique is suitable for adults or children. The tip of each end-plate should point cranially, and the sleeve is now tightened so that the skull is held securely between the end-plate and the sleeve (fig 4). The two arms of the calipers are then joined together by the connecting bar and the screws are firmly tightened. The wounds are closed in layers and are covered with antibiotic ointment and dressings. It is important to tighten all the screws of the Blackburn calipers each day.

When no longer required, the calipers are removed by loosening the screws, removing the connecting bar, loosening the sleeves, and then gently rocking the arm with its pin

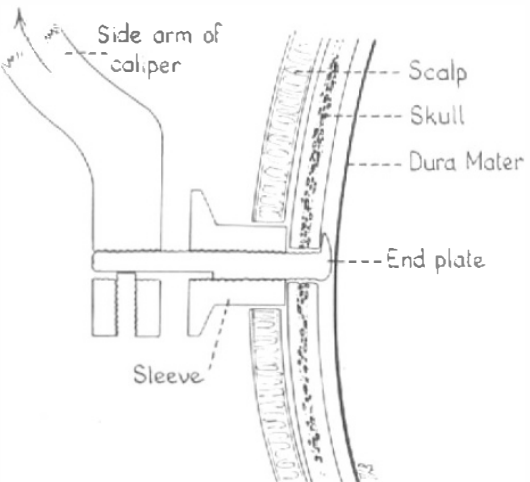

FIG. 4

Diagram of modified Blackburn skull calipers (after Dott), in use. and end-plate out of the skull. The wound is sprayed with an antibiotic and the small hole is left to close without being sutured. No anaesthetic is required for this procedure.

\section{USE OF THE STRYKER TURNING FRAME WITH THE BLACKBURN SKULL CALIPERS}

The patient is now transferred to the posterior frame of the Stryker turning frame, on which he will lie supine. It is important that the canvases straddling the frame are correctly positioned so that the patient's neck, head and heels are not 
directly supported by the frame or pillows, and that the perineal area can be free for toilet purposes. We prefer to cover the canvases with a single or double layer of soft pillows, rather than rely on the rubber mattress which may be supplied with the turning frame. The pillows may be adjusted to maintain the patient's spine in the most desirable position for correction of deformity. Each pillow is covered with a soft plastic waterproof material and this is covered with a pillow case. One pillow is usually placed between the lower limbs, and one between the patient's feet and the foot-rest which is supplied with the frame.

To the head end of each frame is fixed a metal caliper support which was developed by Gillingham from the arrrangement devised by Dott for the plaster shells (p. 279). The connecting bar and side arms of the Blackburn skull calipers rest on this caliper support, which may be adjusted for height and angulation. Then a length of strong wire is fitted to the hook at the centre of the connecting bar of the calipers and is passed through the hole in the centre pin of the disc in the turning frame, over the pulley and attached to weights for pulley traction. The head end of the frame is raised by means of the telescopic legs for counter-traction (fig. 5).

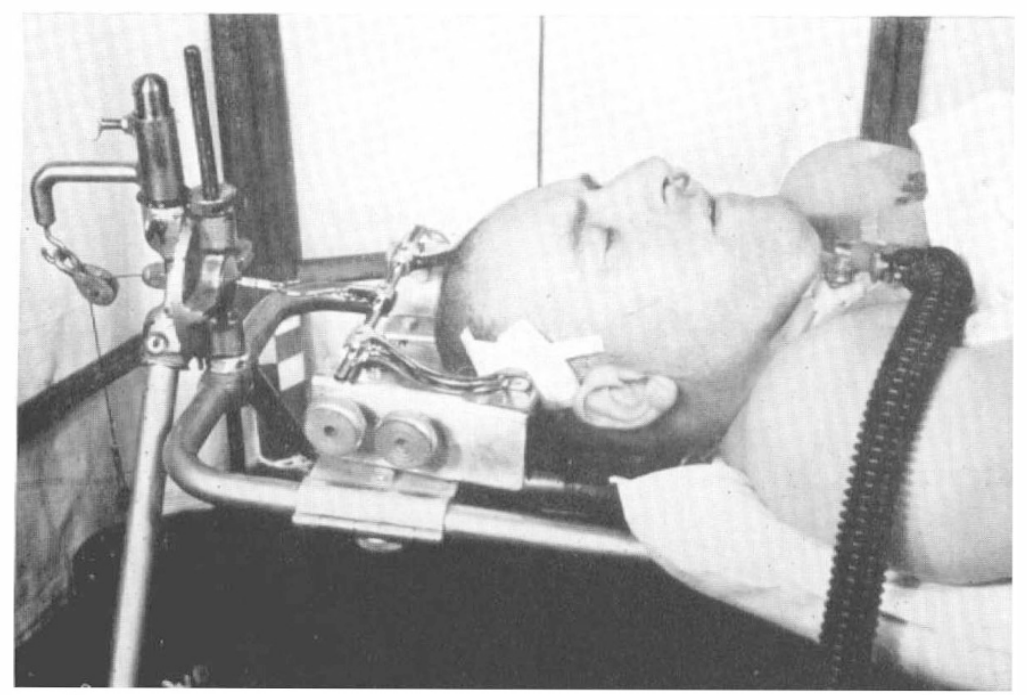

FIG. 5

Head end of Stryker turning frame showing Blackburn skull calipers in use.

To turn the patient the arm boards are removed, a layer of pillows is placed across the patient, and then the anterior frame is applied and is clamped firmly into position over the bolts by means of the locking nuts. In this way the patient, and the Blackburn skull calipers are firmly gripped between the two frames with their calipers supports, and no change in the alignment of the spine can occur when the patient is turned. Also the traction is maintained. Two broad straps are passed around the two turning frames which sandwich the patient. Next, the locks at each end of the frames are released, and the patient is gently rotated so that he comes to lie in the prone position. The frame is then re-locked. The straps and the top (posterior) frame are now removed and the covering pillows are taken 
away. The patient's feet are left pendant, and the patient is covered with a sheet and blankets.

Other attachments for the frame are broad, padded arm rests, a mirror, and a table. Any tendency to adduction spasm of the lower limbs is prevented by keeping them abducted by placing soft pillows between them, and if necessary this part of the frame may be widened with leg boards or a piece of ply board covered with pillows. It is advisable to use the stabiliser arms for fixation of the frame, especially when the patient is being transported on the frame.

The patient is turned as frequently as required, for example two-hourly to begin with, and turning is achieved by two nurses or one nurse and a medical orderly. At intervals during the 24 hours the patient is either placed in a slight head down tilt position by tilting the frame, or extra pillows are added to raise the lower limbs to encourage venous drainage and so help to prevent the development of phlebothrombosis.

The length of time that the patient requires to be managed in this way depends on several factors, including the type of bone and joint injury that the patient has, whether an operation has been carried out or not, the type of operation, and the patient's neurological state. But patients have been very successfully treated by this method for up to three months and some, for example with tuberculous involvement of the cervical spine, for much longer periods (Harris, I963).

\section{ADVANTAGES OF THE METHOD}

When properly used the method is very efficient from the point of view of immobilisation of the patient's cervical spine. It is comfortable for the patient and easy to manage by nursing staff. Radiographs may be taken without any difficulty. Subluxations, dislocations or fracture dislocations of the cervical spine may be reduced by positioning the patient; if necessary counter pressure over the appropriate part of the cervical spine is added, either by placing a firm narrow sandbag resting on a board which straddles this part of the frame, or by using a bridge which may be temporarily fixed to the frame. These reductions are carried out with the patient in the supine position. Any increase in traction is easily obtained by increasing the weights and increasing the tilt of the head end of the Stryker turning frame. The angle of pull can be altered by adjusting the caliper supports. Neck operations may be carried out with the patient on the Stryker turning frame and the Blackburn skull calipers in place, for example an anterior decompression interbody bony fusion procedure, or fixation of the spine posteriorly with methyl methacrylate may be performed. The technique is particularly suitable for patients with injuries involving the atlanto-axial region of the cervical spine.

Complications such as pressure sores, including pressure sores over the occiput, forehead and nose, will not occur, and there appears to be less chance of respiratory and abdominal complications (including pulmonary embolus and paralytic ileus).

The method is very satisfactory for the transportation of a patient with cervical injury, from a hospital near the scene of the accident to the spinal injury centre for example, and even for transportation by air across the Atlantic.

The use of the Blackburn skull calipers/Stryker turning frame technique has greatly lessened the heavy burden on the nursing and rehabilitation staffs and at the 
same time has reduced considerably the incidence of complications in these patients with no sacrifice to the patient's comfort.

\section{DISADVANTAGES OF THE METHOD}

Disadvantages which are more theoretical than real are the narrowness of the frame, and the fact that only two nursing positions, prone and supine, may be obtained. As described above, these have not proved to be difficulties.

\section{CONTRA-INDICATIONS}

There are very few contra-indications to the use of Blackburn skull calipers for patients with cervical spine injury, but the association of a compound fracture of the skull, a scalp burn, an infected scalp laceration, or a head injury where a craniotomy has been necessary, may, if the temporal region is involved, necessitate the use of some other form of skull traction (Schneider, I957).

Again, there are few contra-indications to the use of the Stryker turning frame in patients with cervical spine injury, but if there is an associated head or chest injury the patient may require to be nursed on pillow-packs or on sorbo-rubber packs, by a full complement of trained nursing staff. Another contra-indication is the patient who comes with multiple pressure sores. After these associated injuries or sores have been treated, the patient may be transferred to the Stryker turning frame.

\section{COMPLICATIONS}

These are rare and are usually due to faulty technique or faulty equipment. It is imperative that medical, nursing and rehabilitation staffs are fully conversant with the equipment and the technique, and that the apparatus is carefully checked at regular intervals, if necessary by the hospital engineer.

If improperly applied and checked the calipers may slip out of the skull and may even penetrate the dura mater. Intracranial infection has been reported. When the drill hole in the skull is made the dura mater should not be opened or a leak of cerebrospinal fluid may occur.

Too heavy a pull may result in distraction of the cervical spine, spinal cord and blood vessels, and neurological deterioration may occur. Thus special attention to the patient's neurological state is required when weight traction is being increased.

\section{SUMMARY}

The satisfactory management of a large number of patients with severe injuries of the cervical spine, ranging from the age of 12 to 77 years, bears testimony to the value of the Blackburn skull calipers/Stryker turning frame method of management. Nursing, rehabilitation and medical staff, not forgetting the patients themselves, all appreciate the benefits of this method of treatment, and we feel that with our experience over the years, we can recommend it to others, stressing that as with any form of treatment, careful attention must be paid to every detail of the technique. 


\section{ACKNOWLEDGEMENTS}

We have great pleasure in acknowledging the valuable assistance given to us by nursing staff and by instrument and engineering firms. We are grateful to Professor N. M. Dott and Professor F. J. Gillingham for permission to describe their modifications to the Blackburn skull calipers and Stryker turning frame.

\section{RÉSUMÉ}

Le traitement satisfaisant d'un grand nombre de malades avec atteintes médulaires graves au niveau de la region cervicale, entre 12 et 77 ans, démontre la valeur thérapeutique des étriers de traction du type Blackburn associée a l'utilisation du Stryker frame. Les infirmières, les rééducatrices et le personnel médical, sans oublier les malades eux-mêmes, apprécient les bénefices de cette methode de traitement, et, nous pensons qu'avec notre experience de plusieures années, nous pouvons la recomander à d'autres, en insistant qu'une attention particulière à tous les détails de technique doit être observée.

\section{ZUSAMMENFASSUNG}

Eine Behandlungsmethode mit Blackburn Schädelzug und dem Stryker Drehbett hat sich bei vielen Patienten mit schwerer Halswirbelsäulenverletzung-im Altersbereich von I2 bis 77 Jahren-bewährt.

Schwestern, Physiotherapeuten und Ärzte, besonders aber die Patienten selbst, waren von den Vorteilen der Methode beeindruckt.

Wir empfehlen sie, gestützt auf unsere Erfahrungen in den letzten Jahren, weisen aber darauf hin, dass, wie bei allen Behandlungsmethoden, jede Einzelheit der Technik genau befolgt werden muss.

\section{REFERENCES}

Blackburn, J. D. (1938). Sth. Surg. 7, io.

HARRIS, P. (1963). Royal College of Surgeons of Edinburgh Symposium on Spinal Injuries. In press.

SCHNEIDER, R. C. (1957). Int. Abst. Surg. (Surg. Gynec. Obstet.) 104, 521.

Skinner, G. (1946). Amer. F. Nurs. 46, 5, 2.

SkINNER, G. (I952). Amer. F. Nurs. 52,

Stryker, H. (1939). F. Amer. med. Ass. I13, I73I.

\section{Discussion}

HaRDY, A. G. (England) thought this an important paper with regard to the comments that had been made about the Stryker frame. He thought it should also be taken in a wide context, because there were many methods of nursing procedure, and the important thing was not what one did but the way one did it, the technique and management as a principle. They used to use the Stryker frame and still had a number on the ward but were using them less and less because their particular handling in other ways was better. He would be very interested to hear how long it took to turn a patient and how long it took to turn six, because at the moment at Lodge Moor he had six people on cervical skull traction nursed in bed. Secondly, he wondered how many of the cervical cord injuries with respiratory involvement had had difficulty when they had been prone.

Harris, P. (Scotland) replied that they had not timed the turning of a patient and he thought they should do this. It was a matter of a few minutes. They had had as many as six turning frames in use at the same time at the Royal Infirmary with patients with cervical lesions. He would also like to say that they had to think 
of conditions other than trauma, such as tuberculosis at tnis level, and it had been used for these patients satisfactorily.

With regard to the second question, they had not had any experience with regard to respiratory difficulty. What they had experienced was that cervical traction itself could be dangerous and must be cautiously applied in high cervical lesions, and it was then they had come across respiratory difficulty and other troubles such as hypotension.

GutTmanN, L. (England) said that everybody agreed now that the Stryker frame had its uses and indications. In particular, it was good for transporting a cervical lesion long distances-for instance from Aden and Singapore, etc. He would like to compliment his two colleagues in particular for having revised the original use of the Stryker frame. He did not agree with the original idea of allowing these patients to lie flat for many weeks or months on a Stryker frame. He noted from Mr. Wu's comments that they were very particular in placing the legs in proper position, particularly in abduction; this was important, but he could not see whether they had put pillows under the lumbar spine when the patient was supine. This was important. During his journeys to the U.S.A., where the Stryker frame was used on a much bigger scale than here, what had struck him was that patients who had been lying on Stryker frames for several months had lost the normal curvature of their spine. They had to do everything possible to safeguard the normal curvature of their spine. With regard to time taken in turning, he was very glad that Dr. Hardy had asked this, because when he did this in the early stages he had found that the Stryker frame was not really a time saver, particularly if one had many tetraplegics in the ward.

HARRIS, P. (Scotland) replied that they did in fact put pillows under the lumbar spine. This may not have been brought out in these particular slides but this was the case, as would be borne out by Mr. W. Kerr's experience in the Edenhall Spinal Injuries Unit.

KERR, W. S. (Scotland) added that they also avoided knee hyperextension.

Harris, P. (Scotland) said that with regard to positioning of these patients, the Circo electric bed which they were going to mention had some place in the treatment of patients with severe cervical spine injuries, mainly from the point of view of posture for lung drainage and to help overcome postural hypotension. The other point was that it was not just the Stryker frame but the whole technique which should be considered.

WALSH, J. J. (England) remarked that Mr. Wu had mentioned his use of the Blackburn caliper. For a number of years, he had used this on head traction and had always felt that he was very lucky indeed not to get extradural sepsis. Mr. Wu had also mentioned low grade infection which did occur and he did feel that a caliper in connection with the extradural space if left there for several weeks was a potential danger. They had in fact had admitted a case at Stoke Mandeville with a Blackburn caliper in position who did develop a brain abscess. He personally used Cones' head tongs, which he found much more satisfactory; firstly, they went through only the outer table so that one did not open the extradural space, secondly they were much easier to put on for that reason and thirdly they were very much easier to remove than the Blackburn tongs.

HARris, P. (Scotland) said that extradural infection must be a rarity although a possibility, and one had seen this in a patient with calipers when they had been inserted into the diploë, resulting in a low grade osteomyelitis with extradural 
infection and indeed cerebral thrombophlebitis. However, he did not think that the fact that they were actually through the bone should deter them from using them.

HaRdy, A. G. (England) said they had experienced two unhappy episodesoddly enough one with a Blackburn and the other with a Cones' caliper. The one with a Blackburn produced regrettably a parietal abscess, which in spite of aspiration was eventually excised by the neurosurgeons and they had a paraplegia turned into a triplegia. The other one with the Cones' caliper slipped and went in, and they had an extradural infection. However, these were two cases out of 135 or so over many years, and he thought that if one went on long enough inevitably one would catch something.

GutTMAnN, L. (England) said he was worried about the prone position in high cervical lesions, especially in cases who developed an ileus or were in respiratory distress. He personally would not dare to put high cervical lesions in prone position, and in his opinion one should add this as a contra-indication to that already mentioned by Mr. Harris and Mr. Wu.

Wu, P. (Scotland) said they looked after the Blackburn caliper every day pretty carefully; they cleaned up the skull wounds every day and sprayed with Polybactrin locally to make sure that no infection settled.

\title{
MYOTOMY OF ILIOPSOAS AND OBLIQUUS EXTERNUS ABDOMINIS FOR SEVERE SPASTIC FLEXION CONTRACTURE AT THE HIP
}

\author{
By L. S. Michaelis, M.D. (Berlin), L.R.C.P. \& S. (Ed.) \\ National Spinal Injuries Centre, Stoke Mandeville Hospital, England
}

\section{INTRODUCTION}

THE treatment of severe spastic flexion contracture at the hip in paraplegic and tetraplegic patients poses a number of problems. Passive extension-exercises alone are generally unable to improve the condition in these cases and may even increase the lordosis of the lumbar spine already caused by the contracture of the iliopsoas.

In complete lesions, particularly in women and older men, the alcohol block is the method of choice, but in younger men one will hesitate to sacrifice potency and a well-established automatic bladder. Most difficult to achieve is correction of the contracture and reduction of spasticity in incomplete lesions.

This is a report on the results of proximal myotomy of the iliopsoas on 14 severely spastic patients with extreme flexion-contracture at the hip carried out over the last four years. In io patients the operation was done bilaterally so that the results of 24 operations can be reviewed. The age of the patients ranged from I 3 to 57 years. In seven paraplegia or tetraplegia was due to trauma, in the other seven to either tumor or disease of the cord or spine. The neurological levels were cervical in four, upper thoracic in four and lower thoracic in six cases. In all patients but two the lesions were incomplete. In the majority of cases iliopsoas 